\title{
Randomized Clinical Trials and Real World Prospective Observational Studies on Bevacizumab, PARP Inhibitors, and Immune Checkpoint Inhibitors in the First-Line Treatment of Advanced Ovarian Carcinoma: A Critical Review
}

\author{
ANGIOLO GADDUCCI and STEFANIA COSIO \\ Department of Clinical and Experimental Medicine, \\ Division of Gynecology and Obstetrics, University of Pisa, Pisa, Italy
}

\begin{abstract}
Platinum/paclitaxel-based chemotherapy is able to obtain a clinical response in up to $80 \%$ of patients with advanced ovarian carcinoma, but most of them will subsequently develop recurrent disease. Several therapeutic approaches, including prolonged administration of the firstline regimen and the concomitant or sequential addition of a third cytotoxic agent to standard chemotherapy, failed to improve the clinical outcome of patients. In the last years, the implementation of the biological knowledge on ovarian carcinoma and the introduction of bevacizumab (BEV) and poly(ADP-ribose) polymerase inhibitors (PARPi) in first-line treatment have improved patient prognosis. In this review, we have analyzed the randomized clinical trials and real world observational studies on these issues, with the aim to suggest an algorithm for a rational use of BEV and PARPi in patients with newly diagnosed advanced ovarian carcinoma.
\end{abstract}

GLOBOCAN estimates of the worldwide incidence and mortality of 36 cancers in 185 countries have shown 295,414 new cases of ovarian carcinoma and 184,799 deaths due to this malignancy in 2018 (1). After Kurman and Shih's proposal of a dualistic model for ovarian carcinogenesis, several molecular and histopathologic studies have provided novel important

This article is freely accessible online.

Correspondence to: Angiolo Gadducci, Department of Clinical and Experimental Medicine, Division of Gynecology and Obstetrics, University of Pisa, Pisa 56127, Italy. Tel: +39 50992609, e-mail: angiolo.gadducci@unipi.it

Key Words: Ovarian carcinoma, chemotherapy, bevacizumab, PARPinhibitors, olaparib, niraparib, immune-check point inhibitors, review. insights into the molecular pathogenesis of this disease (2). Nowadays ovarian carcinomas can be subdivided into five histological subtypes, termed high-grade serous (70\%), endometrioid $(10 \%)$, clear cell $(10 \%)$, mucinous $(3 \%)$, and low-grade serous $(<5 \%)$ carcinomas (3). The large majority of these malignancies are high-grade tumors, with aggressive clinical behavior and advanced stage at presentation.

Primary debulking surgery (PDS) followed by paclitaxel (PTX)/carboplatin (CBDCA)-based chemotherapy is the best treatment modality for advanced ovarian carcinoma, if the resection of all macroscopic disease can be obtained with an acceptable operative morbidity (4). Neoadjuvant chemotherapy (NACT) followed by interval debulking surgery (IDS) and additional chemotherapy is usually suggested for patients not fit for primary aggressive surgery due to either advanced age, frailty, poor performance status and comorbidities or disease spread that is unlikely to be optimally debulked $(5,6)$. Histopathologic diagnosis of ovarian carcinoma based on surgical or diagnostic imagingtechnique guided tissue biopsies is recommended before starting NACT. Whenever biopsy is not feasible, the diagnosis should be based on the cytological examination of peritoneal or pleural effusion combined with a serum CA125/CEA ratio $>25$, and possibly on gastroscopy and colonoscopy negative for primary gastro-enteric tumors (7).

Standard chemotherapy is able to achieve a clinical response rate of $59-81.4 \%$ with a median progression-free survival (PFS) of 15.5-22 months and a median overall survival (OS) of 3144 months (8-13). Approximately $75 \%$ of the responding patients will develop recurrent /progressive disease within a median time of 18-24 months, and different consolidation or maintenance treatments, such as whole abdomen radiotherapy, intraperitoneal chemotherapy, high-dose chemotherapy with hematopoietic support, prolonged administration of the firstline regimen and the concomitant or sequential addition of a 
third cytotoxic agent to standard PTX/CBDCA, failed to improve the clinical outcomes (14-19).

In recent years the implementation of biological knowledge on ovarian carcinoma and especially on the predictive and prognostic relevance of BRCA and homologous recombination status, as well as the addition of biological agents, such as BEV and poly(ADP-ribose) polymerase inhibitors (PARPi) to first-line chemotherapy have improved patient prognosis.

In this review we analyze the clinical trials on these issues, in order to offer a possible algorithm that may help the clinicians in the rational use of BEV and PARPi in patients with newly diagnosed advanced ovarian carcinoma.

\section{Trials With Bevacizumab}

Gynecologic Oncology Group (GOG) 218 phase III trial randomized patients with advanced ovarian carcinoma to receive i) PTX+CBDCA for 6 cycles with placebo added in cycles 2 through 22; or ii) the same chemotherapy plus BEV added in cycles 2 through 6 and followed by placebo added in cycles 7 through 22; or iii) the same chemotherapy plus BEV added in cycles 2 through 22 (20) (BEV throughout). The BEV-throughout arm achieved a better PFS compared with the chemotherapy arm alone [hazard ratio $(\mathrm{HR})=0.717$, $p<0.001]$, which was the primary endpoint of the study (Table I and Table II).

Grade $\geq 2$ hypertension was significantly more common with BEV than with placebo, whereas there were no significant differences among the three arms in terms of severe gastrointestinal adverse events or proteinuria. The final analysis of the study confirmed the lack of OS benefit from both concurrent BEV and concurrent and maintenance BEV compared with chemotherapy only in the whole population $(\mathrm{HR}=1.06,95 \% \mathrm{CI}=0.94-1.20$ and $\mathrm{HR}=0.96$, 95\% CI=0.85-1.09, respectively) (21). However, in an exploratory subset analysis the BEV-throughout arm was associated with a better OS compared with the chemotherapy only arm in patients with stage IV disease (median, 42.8 versus 32.6 months, $\mathrm{HR}=0.75 ; 95 \% \mathrm{CI}=0.59-0.95$ ).

In the International Collaboration on Ovarian Neoplasms (ICON7) trial, patients with high-risk stage IA-IIA or stage IIB-IV ovarian carcinoma were randomized to PTX + CBDCA for 6 cycles or the same chemotherapy plus BEV $7.5 \mathrm{mg} / \mathrm{kg}$ given concurrently for 5 or 6 cycles and continued for 12 additional cycles (22) (Table I). PFS was better for the BEV arm $(\mathrm{HR}=0.81, p=0.004)$, and the PFS difference between BEV- and non-BEV-treated patients peaked at 12 months, corresponding to the end of BEV treatment, with an improvement in PFS at this time of approximately $15.1 \%$ but afterwards this advantage tended to decrease (Table II). In a subsequent exploratory analysis, the addition of BEV improved OS (median, 39.7 versus 30.2 months, $p=0.03$ ) in a subgroup of 502 high-risk patients, defined as those with stage IV disease, or suboptimally debulked $(>1 \mathrm{~cm})$ stage III disease, or inoperable disease (23). In a further update of the trial, the PFS benefit from the antiangiogenic agent was $0.77(95 \% \mathrm{CI}=0.59-0.99)$ for the patients with stage IIIB-IV and no macroscopic RD and 0.81 $(95 \% \mathrm{CI}=0.69-0.95)$ for those with stage IIIB-IV disease and macroscopic RD (24).

Real world data were consistent with the results of these two randomized trials (25-29) (Table III).

The OTILIA prospective observational study has been planned to assess the safety, efficacy, quality of life and predictive/selection factors for BEV in combination with PTX+CBDCA in first-line treatment of 1090 patients with advanced ovarian carcinoma. Patient recruitment was completed in September 2019 but no study results have been yet posted on ClinicalTrials.gov (25).

The OSCAR study assessed 229 British women with highrisk stage IIIB-IV ovarian carcinoma who received BEV [7.5 or $15 \mathrm{mg} / \mathrm{kg}$ every 3 weeks (Q3W)] concurrently with firstline chemotherapy and sequentially as maintenance therapy (26). In the whole population the median PFS was 15.4 months similar to that of the high-risk subgroup of the ICON7 trial. Median PFS was 20.8, 16.1 and 13.6 months, respectively, in patients who underwent PDS, IDS and no surgery, and the most frequent grade 3-4 adverse event was hypertension (16\%).

The JGOG3022 prospective Japanese study by Komiyama et al. (27) assessed 293 patients with stage III-IV ovarian carcinoma who received PTX+CBDCA + concurrent and maintenance $\mathrm{BEV}$ with the same schedule and dosages as the GOG 218 trial. Median PFS was 16.3 months and response rate among the patients with measurable disease was $77.5 \%$, ranging from $81.7 \%$ in patients with serous histology to $63.6 \%$ in those with clear cell histology. A phase III trial of first-line chemotherapy in ovarian clear cell carcinoma reported a response rate of $46.7 \%$ to PTX+CBDCA (30). Therefore, the addition of BEV appeared to increase the anticancer activity of standard chemotherapy in this chemoresistant histotype. In the study of Komiyama et al . (27) grade $>3$ hypertension, proteinuria, gastrointestinal events and thromboembolic events were reported in $23.2 \%$, $12.6 \%, 1 \%$ and $1.4 \%$ of the cases, respectively.

The real world ROBOT trial reviewed 381 consecutive patients with ovarian carcinoma who received first-line PTX/CBDCA-based chemotherapy without BEV $(n=304)$ or with BEV $(\mathrm{n}=77)$ at doses ranging from 7.5 to $15.1 \mathrm{mg} / \mathrm{kg}$ (28). One hundred and forty-seven $(38.6 \%)$ patients were in stage I-II, $234(61.4 \%)$ were in stage III-IV, and of these 116 were at high-risk according to ICON7 criteria. The addition of BEV to chemotherapy showed a trend towards a better PFS in the whole group of patients with advanced disease (median, 11.6 versus 9.3 months, $\mathrm{HR}=0.84,95 \% \mathrm{CI}=0.6$ - 
Gadducci and Cosio: Bevacizumab, PARP Inhibitors, and Immune Checkpoint

Inhibitors in the First-Line Treatment of Ovarian Carcinoma (Review)

Table I. Incorporation of BEV in first-line therapy of ovarian carcinoma: Randomized trials. Tumor stage and randomization arms.

\begin{tabular}{|c|c|c|c|c|}
\hline Trial & Pts & Stage & Regimen & arm \\
\hline GOG 218 & 1873 & $\begin{array}{l}\text { III (macroscopic RD) } \\
\text { IV }\end{array}$ & 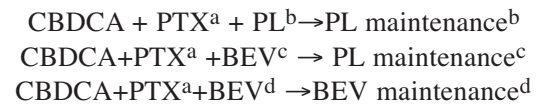 & $\begin{array}{c}\text { Control } \\
\text { BEV-initiation } \\
\text { BEV-throughout }\end{array}$ \\
\hline ICON7 & 1528 & $\begin{array}{l}\text { I-IIa (G3, clear cell) } \\
\text { IIb-IV }\end{array}$ & $\begin{array}{c}\text { CBDCA+PTX } \\
\text { CBDCA+PTX }+ \text { BEV }^{\mathrm{f}} \rightarrow \text { BEV maintenance }^{\mathrm{f}}\end{array}$ & \\
\hline
\end{tabular}

${ }^{a}$ CBDCA AUC 6 +PTX $175 \mathrm{mg} / \mathrm{m}^{2}$ Q3w $\times 6$ cycles; ${ }^{b}$ PL Q3w added in cycles 2 through 22; ${ }^{\mathrm{c}} \mathrm{BEV}(15 \mathrm{mg} / \mathrm{kg}$ Q3w) added in cycles 2 through 6 and PL added in cycles 7 through 22; ${ }^{B E V}(15 \mathrm{mg} / \mathrm{kg} \mathrm{Q} 3 \mathrm{w})$ added in cycles 2 through 22; ${ }^{\mathrm{C}} \mathrm{CBDCA}$ AUC 5-6 + PTX $175 \mathrm{mg} / \mathrm{m} 2 \mathrm{Q} 3 \mathrm{w} \times 6 \mathrm{cycles}$; ${ }_{\mathrm{f}} \mathrm{BEV}(7.5 \mathrm{mg} / \mathrm{kg} \mathrm{Q} 3 \mathrm{w})$ given concurrently for 5-6 cycles and continued for 12 additional cycles. CBDCA: Carboplatin; PTX: paclitaxel; PL: placebo; BEV: bevacizumab; Q3W: every 3 weeks; AUC: area under curve; RD: residual disease.

Table II. Incorporation of BEV in first-line therapy of ovarian carcinoma: Randomized trials. Clinical outcome and BEV-related severe adverse events.

\begin{tabular}{|c|c|c|c|c|c|c|c|c|c|c|c|}
\hline \multirow[t]{2}{*}{ Trial } & \multirow[t]{2}{*}{ Arm } & \multirow{2}{*}{$\begin{array}{c}\text { PFS } \\
\text { median }\end{array}$} & \multirow{2}{*}{$\begin{array}{c}\text { OS } \\
\text { median }\end{array}$} & \multirow{2}{*}{$\begin{array}{l}\mathrm{GI}^{\mathfrak{c}} \\
\geq 2\end{array}$} & \multirow{2}{*}{$\begin{array}{l}\text { HT } \\
\geq 2\end{array}$} & \multirow{2}{*}{$\begin{array}{c}\text { Proteinuria } \\
\quad \geq 3\end{array}$} & \multirow[t]{2}{*}{ VT } & \multirow[t]{2}{*}{ AT } & \multicolumn{2}{|c|}{ Bleeding } & \multirow{2}{*}{$\begin{array}{l}\text { Wound } \\
\text { disruption }\end{array}$} \\
\hline & & & & & & & & & CNS & No CNS & \\
\hline \multirow[t]{3}{*}{ GOG 218} & Control & 10.3 & 39.3 & $1.2 \%$ & $7.2 \%$ & $0.7 \%$ & $5.8 \%$ & $0.8 \%$ & $0 \%$ & $0.8 \%$ & $2.8 \%$ \\
\hline & BEV-initiation & $11.2^{\circ}$ & $38.7^{\circ \circ}$ & $2.8 \%$ & $16.5 \%$ & $0.7 \%$ & $5.3 \%$ & $0.7 \%$ & $0 \%$ & $1.3 \%$ & $3.6 \%$ \\
\hline & BEV-throughout & $14.1^{*}$ & $39.7 * *$ & $2.6 \%$ & $22.9 \%^{\wedge}$ & $1.6 \%$ & $6.7 \%$ & $0.7 \%$ & $0.3 \%$ & $2.1 \%$ & $3.0 \%$ \\
\hline \multirow[t]{2}{*}{ ICON7 } & Control & 20.3 & NR & $<1 \%$ & $<1 \%$ & $<1 \%$ & $4 \%$ & $<2 \%$ & $0 \%$ & $<6 \%$ & $<3 \%$ \\
\hline & BEV-throughout & $21.8 \S$ & $\mathrm{NR} \S \S$ & $1 \%$ & $6 \%$ & $1 \%$ & $6 \%$ & $4 \%$ & $1 \%$ & $<8 \%$ & $5 \%$ \\
\hline
\end{tabular}

Primary endpoint: versus control: $\mathrm{HR}=0.908(95 \% \mathrm{CI}=0.795-1.040)^{\circ}, \mathrm{HR}=1.036(95 \% \mathrm{CI}=0.827-1.297)^{\circ}$; versus control: $\mathrm{HR}=0.717(95 \% \mathrm{CI}=0.625-$ $0.824)^{*}, \mathrm{HR}=0.915$ (95\% CI=0.727-1.152; $\left.p=0.45\right)^{* *}$; versus control: $p<0.05^{\wedge}$; versus control: $\left.\mathrm{HR}=0.81 ; 95 \% \mathrm{CI}=0.70-0.94\right) \S ; \mathrm{HR}=0.85$ (95\%CI $=0.69-$ 1.04 )§. çGastro-intestinal adverse events: perforation, fistula, necrosis of anastomotic leak. PFS: progression fee survival; OS: overall survival; GI: gastrointestinal; HT: hypertension; VT: venous thrombosis; AT: arterial thrombosis; CNS: central nervous system.

$1.19)$ and significantly improved PFS in high-risk patients (median, 10.5 versus 6.0 months, $\mathrm{HR}=0.62,95 \% \mathrm{CI}=0.39$ 0.97). Moreover, there was a trend towards a better OS for BEV-treated patients both in the whole advanced stage subgroup (median, not reached versus 43.7 months, $\mathrm{HR}=0.69,95 \% \mathrm{CI}=0.43-1.11)$ and in the high-risk subset (median, not reached versus 34.7 months, $\mathrm{HR}=0.61$, $95 \% \mathrm{CI}=0.33-1.10)$. Low rates and grades of BEV-related adverse events were recorded.

ROSiA is a prospective single-arm phase $3 \mathrm{~b}$ study which assessed the efficacy and safety of BEV-containing treatment in 1021 patients with grade 3 stage I-IIA or stage IIB-IV ovarian carcinoma without signs or symptoms of gastrointestinal obstruction or history of abdominal fistula, gastrointestinal perforation, or intra-abdominal abscess within the preceding 6 months (29). Eligibility criteria were designed to recruit a patient population similar to that enrolled in the ICON7 trial. After surgery, patients received BEV $(15 \mathrm{mg} / \mathrm{kg})$ $(89 \%)$ or $7.5 \mathrm{mg} / \mathrm{kg}(11 \%)$ Q3W concurrently with PTX (175 $\mathrm{mg} / \mathrm{m}^{2} \mathrm{Q} 3 \mathrm{~W}$ or $80 \mathrm{mg} / \mathrm{m}^{2}$ weekly) + CBDCA (AUC 5-6 Q3W) for 4-8 cycles, followed by BEV maintenance for up to 24 months. This antiangiogenic agent was administered for more than 1 year in $62 \%$ of the patients, more than 15 months in $53 \%$, and more than 2 years in $29 \%$. Median PFS was 25.5 months, the longest reported in the literature, in the whole series, 18.3 months in high-risk patients and 32.0 months in non-high-risk patients according to ICON7 criteria. Grade $\geq 3$ hypertension, proteinuria and gastrointestinal events occurred in $25 \%, 4 \%$ and $1.4 \%$ of the patients, respectively. Typically, hypertension first appeared during earlier BEV cycles, with a median time to onset of 2.1 months, whereas proteinuria showed a more linear relationship between first onset and duration of exposure for the first 24 months. Therefore, extended BEV-containing therapy appeared to be both tolerable and feasible.

The MITO 16A- MaNGO OV2A phase 4 trial included 398 patients with advanced ovarian carcinoma who received CBDCA (AUC 5) + PTX $\left(175 \mathrm{mg} / \mathrm{m}^{2}\right)+\mathrm{BEV}(15 \mathrm{mg} / \mathrm{kg})$ Q3W for 6 cycles followed by BEV maintenance until 22 cycles (31). After a median follow-up of 32.3 months, median PFS was 20.8 months and median OS was 41.1 months and toxicity profile wase comparable to previous 
Table III. Incorporation of BEV in first-line therapy of ovarian carcinoma: Real World observational studies.

\begin{tabular}{|c|c|}
\hline NCT01697488: & $\begin{array}{l}\text { Non-interventional surveillance study on first-line bevacizumab in combination with carboplatin/paclitaxel } \\
\text { in patients with advanced epithelial ovarian, fallopian tube or primary peritoneal cancer (OTILIA) }\end{array}$ \\
\hline NCT01863693: & $\begin{array}{l}\text { Observational study of bevacizumab in combination with chemotherapy as first-line treatment in patients } \\
\text { with advanced ovarian cancer (OSCAR 1) }\end{array}$ \\
\hline JGOG3022: & $\begin{array}{l}\text { Bevacizumab combined with platinum-taxane chemotherapy as first-line treatment for advanced } \\
\text { ovarian cancer: a prospective observational study of safety and efficacy in Japanese patients }\end{array}$ \\
\hline ROBOT TRIAL: & $\begin{array}{l}\text { Real-world study of adding bevacizumab to chemotherapy for ovarian, tubal, and peritoneal cancer as } \\
\text { front-line or relapse therapy }\end{array}$ \\
\hline NCT01239732: & $\begin{array}{l}\text { Global study to assess the addition of bevacizumab to carboplatin and paclitaxel as front-line treatment of } \\
\text { epithelial ovarian cancer, fallopian tube carcinoma or primary peritoneal carcinoma (ROSiA) }\end{array}$ \\
\hline NCT01706120: & $\begin{array}{l}\text { Study of clinical and biological prognostic factors in patients with ovarian cancer receiving } \\
\text { carboplatin+paclitaxel with bevacizumab (MITO16/MANGO-2) }\end{array}$ \\
\hline NCT0146289: & $\begin{array}{l}\text { A prospective randomised phase III trial to evaluate optimal treatment duration of first-line bevacizumab } \\
\text { in combination with carboplatin and paclitaxel in patients with primary epithelial ovarian, fallopian tube or } \\
\text { peritoneal cancer (BOOST) }\end{array}$ \\
\hline
\end{tabular}

data. Neither baseline blood pressure nor the development of hypertension during BEV had prognostic relevance.

The NCT01462890 prospective phase III trial randomly allocated 927 women with stage IIB-IV ovarian carcinoma treated with PDS followed by PTX $\left(175 \mathrm{mg} / \mathrm{m}^{2}\right)+$ CBDCA (AUC 5) + BEV (15 mg/kg) Q3W to receive BEV for either 15 months or 30 months (32). There was no difference between the two arms in terms of both PFS (median, 24.2 versus 26.0 months; $\mathrm{HR}=0.99,95 \% \mathrm{CI}=0.85-1.15$ ) and $\mathrm{OS}$ (median, 54.3 versus 60.0 months; $\mathrm{HR}=1.04 ; 95 \% \mathrm{CI}=0.87-1.23$ ).

The non-comparative phase II ANTHALYA trial randomized 95 patients in a ratio 2:1 to receive either NACT with CBDCA (AUC 5) + PTX $\left(175 \mathrm{mg} / \mathrm{m}^{2}\right) \mathrm{Q} 3 \mathrm{~W}$ for 4 cycles or the same NACT plus BEV (15 mg/kg) Q3W on cycles $1-3$ prior to IDS (33). The BEV-arm achieved a complete response rate of $58.6 \%$ with a lower confidence limit of $47.0 \%$, which was higher than the threshold of $45 \%$ established on the basis of the complete response rate in the Vergote et al.'s randomized trial of NACT followed by IDS (46.3\%) (34). The incidence of post-surgical adverse events, mainly represented by wound, infectious, and gastrointestinal complications, was similar in the two arms. Therefore, the addition of BEV to NACT appeared to be safe, although the evidence that it improves the clinical outcome of patients is still lacking.

\section{Trials With PARP Inhibitors}

Four phase III randomized trials have demonstrated the efficacy and acceptable toxicity profile of the introduction of PARPi in the first-line treatment of advanced ovarian carcinoma (Table IV and Table V).

SOLO-1 trial randomly assigned patients with germline or somatic BRCA mutation in complete or partial response after first-line platinum-based chemotherapy to receive either olaparib or placebo as maintenance (35). In the primary investigator analysis 3-years PFS was $60 \%$ and $27 \%$ for the olaparib arm and placebo arm, respectively $(\mathrm{HR}=0.30$; $p<0.001)$. The blinded independent central review confirmed these results: 3-year PFS was $69 \%$ for olaparib compared with $35 \%$ for placebo $(\mathrm{HR}=0.28 ; 95 \% \mathrm{CI}=0.20-0.39, p<0.001)$. At an interim analysis 3-year OS was similar in the two groups ( $84 \%$ versus $80 \%$; $\mathrm{HR}=0.95 ; 95 \% \mathrm{CI}=0.60-1.53$ ). $\mathrm{G} 3-4$ anemia was the most common adverse event in the olaparib group $(22 \%)$. Myeloid acute leukemia, novel primary cancer, and pneumonitis or interstitial lung disease occurred in $1 \%, 2 \%$, and $2 \%$ of patients, respectively, in the olaparib arm, compared to $0 \%, 2 \%$, and $0 \%$ of those, respectively, in the placebo arm. All three cases of acute myeloid leukemia were diagnosed more than 30 days after olaparib treatment completion. On December 2018, the U.S. Food and Drug Administration (FDA) granted approval to olaparib monotherapy for first-line maintenance of $B R C A$-mutated advanced ovarian carcinoma. An update of the study confirmed that olaparib significantly improved PFS (median, 56 versus 13.8 months; 5-year PFS, $48 \%$ versus $21 \%, \mathrm{HR}=0.33,95 \% \mathrm{CI}=0.25-0.43) \quad(36) . \mathrm{A}$ subgroup analysis found that olaparib maintenance reduced the risk of progression or death in patients who underwent PDS $(\mathrm{HR}=0.31 ; 95 \% \mathrm{CI}=0.21-0.46)$ and in those who underwent IDS $(\mathrm{HR}=0.37 ; 95 \% \mathrm{CI}=0.24-0.58)$, in patients with $\mathrm{RD}$ after surgery $(\mathrm{HR}=0.44 ; 95 \% \mathrm{CI}=0.25-0.77)$ and in those without $\mathrm{RD}$ after surgery $(\mathrm{HR}=0.33 ; 95 \% \mathrm{CI}=0.23-0.46)$, in complete responders $(\mathrm{HR}=0.34,95 \% \mathrm{CI}=0.24-0.47)$ and in partial responders at baseline $(\mathrm{HR}=0.31 ; 95 \% \mathrm{CI}=0.18-0.52)$, and in patients with $B R C A 1$ mutation $(\mathrm{HR}=0.41 ; 95 \% \mathrm{CI}=0.30-0.56)$ as well as in those with $B R C A 2$ mutations $(\mathrm{HR}=0.20$; 95\% CI=0.10-0.37) (37). These PFS improvements were obtained without clinically meaningful changes in healthrelated quality of life (38).

PRIMA trial randomized patients in clinical response after 6 to 9 cycles of first-line platinum-based chemotherapy to 
Table IV. PARP inhibitors in first-line therapy of ovarian carcinoma: Randomized trials. Patient characteristics and randomization arms.

\begin{tabular}{|c|c|c|c|c|c|c|c|c|}
\hline Trial & Arm & Randomization & pts & Stage IV & BRCA & PDS & No RD & $\begin{array}{l}\text { Clinical CR } \\
\text { after CT }\end{array}$ \\
\hline SOLO-1 & $\begin{array}{c}\text { Olapariba } 300 \mathrm{mg} \text { bid } \\
\text { PL }^{\mathrm{a}}\end{array}$ & $2: 1$ & 391 & $17 \%$ & $100 \%$ & $63 \%$ & $22 \%$ & $82 \%$ \\
\hline PAOLA1 & $\begin{array}{c}\text { Olaparib } 300 \mathrm{mg} \text { bid up to } \\
24 \text { months }+ \text { BEV } 15 \mathrm{mg} / \mathrm{kg} \\
\text { q3w up to } 15 \text { months } \\
\text { PL bid up to } 24 \text { months }+ \\
\text { BEV } 15 \mathrm{mg} / \mathrm{kg} \mathrm{q} 3 \mathrm{w} \text { up to } 15 \text { months }\end{array}$ & $2: 1$ & 1806 & $30 \%$ & $29 \%$ & $51 \%$ & $35 \%$ & $73 \%$ \\
\hline PRIMA & $\begin{array}{l}\text { Niraparib } 300 \text { mgb daily up to } 36 \text { months } \\
\text { PL daily up to } 36 \text { months }\end{array}$ & $2: 1$ & 733 & $35 \%$ & $30 \%$ & $33 \%$ & NA & $69 \%$ \\
\hline VELIA & $\begin{array}{c}\text { CBDCA + PTXc + PLd } \rightarrow \text { PLe (Control) } \\
\text { CBDCA + PTXc + VELf } \rightarrow \text { PLe (VEL-initiation) } \\
\text { CBDCA + PTXc + VELf } \rightarrow \text { VELg (VEL-throughout) }\end{array}$ & $1: 1: 1$ & 1140 & $23 \%$ & $26 \%$ & $67 \%$ PDS & $47 \%$ & NA \\
\hline
\end{tabular}

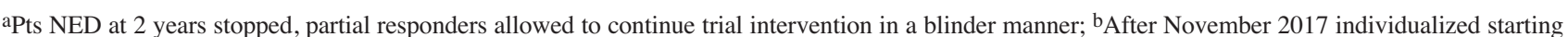
dose of $200 \mathrm{mg}$ for pts with baseline body weight $<77 \mathrm{~kg}$ or platelet count $<150,000 \mathrm{~mm}^{3}$; $175 \mathrm{mg} / \mathrm{m}^{2} \mathrm{q} 3 \mathrm{w}$ or $80 \mathrm{mg} / \mathrm{m}^{2}$ weekly + CBDCA AUC 6 q3w; dPL concomitant with chemotherapy; ePL as maintenance; fVEL (150 mg bid) concomitant with chemotherapy; gVEL (300-400 mg bid) as maintenance. Pts: Patients; PDS: primary debulking surgery; RD: residual disease; CR: complete response; CT: chemotherapy, PL: placebo; bid: twice daily, BEV: bevacizumab; Q3W: every 3 weeks; NA: not available; IDS; interval surgery; CBDCA: carboplatin; PTX: paclitaxel; VEL: veliparib; AUC: area under curve.

receive to either niraparib or placebo as maintenance (39). Most patients had stage III disease with visible RD after PDS, inoperable stage III disease or stage IV disease, and had undergone NACT followed by IDS. Tumor samples underwent central testing to identify those with homologousrecombination deficiency (HRD), according to myChoice assay based on three genomic lesions, i.e., loss of heterozygosity $(\mathrm{LOH})$, telomeric allelic imbalance, and largescale state transitions. HRD was defined as the presence of $B R C A$ mutation, myChoice assay score $\geq 42$ or both. A hierarchical-testing method was performed for the primary end point in patients with HRD, followed by a test in the overall population. Niraparib improved PFS both in patients with HRD $(\mathrm{HR}=0.43, p<0.001)$ and in overall population (HR=0.62; $p<0.001)$. Moreover, prespecified exploratory analyses revealed that niraparib maintenance was associated with a significantly longer PFS in patients with HRD and $B R C A$ mutation $(\mathrm{HR}=0.40)$, in those with HRD but without $B R C A$ mutation $(\mathrm{HR}=0.50)$ and in those with homologousrecombination proficiency $(\mathrm{HRP})(\mathrm{HR}=0.68)$. Moreover, niraparib improved PFS also in other subsets of patients with poor prognosis, such as those who underwent NACT (median, 13.9 versus 8.2 months; $\mathrm{HR}=0.59$; 95\% CI=0.46$0.76)$ and those with a partial response to chemotherapy (median, 8.3 versus 5.6 months; $\mathrm{HR}=0.60$; 95\% $\mathrm{CI}=0.43$ $0.85)$. The interim analysis of 24 month-OS data failed to detect a benefit from niraparib both in the overall population ( $84 \%$ versus $77 \%$; $\mathrm{HR}=0.70 ; 95 \% \mathrm{CI}=0.44-1.11)$ and in $\mathrm{HRD}$ patients $(91 \%$ versus $85 \%, \mathrm{HR}=0.61 ; 95 \% \mathrm{CI}=0.27-1.39) . \mathrm{G} 3-$ 4 anemia and thrombocytopenia were the most common adverse events in niraparib arm, and myelodysplastic syndrome occurred in a patient treated with this PARPi. The populations of SOLO-1 and PRIMA trials were quite different, not only as for $B R C A$ or HRD status. More patients in SOLO-1 than in PRIMA had stage III disease (83\% versus $65 \%)$ and underwent PDS with no macroscopic RD (44\% versus $0.4 \%$ ). However, subgroup analysis showed a similar lower risk of progression (36) in olaparib-treated patients with RD after surgery in the SOLO-1 trial and in niraparibtreated patients with $B R C A$ mutation and RD after surgery in the PRIMA trial $(\mathrm{HR}=0.44,95 \% \mathrm{CI}=0.25-0.77$, and, respectively, $\mathrm{HR}=0.40,95 \% \mathrm{CI}=0.27-0.62$ ).

A post-hoc analysis of the PRIMA trial presented by O'Cearbhaill at the Society of Gynecologic Oncology (SGO) meeting 2021 showed that niraparib treatment reduced the risk of progression compared with placebo in the whole population of patients who underwent PDS (median PFS, 13.7 versus 8.2 months, $\mathrm{HR}=0.67,95 \% \mathrm{CI}=0.468-0.964)$ and in the patients who underwent PDS with visible RD (median PFS, 11.8 versus 7.8 months, $\mathrm{HR}=0.58,95 \% \mathrm{CI}=0.391-$ 0.864). Moreover, niraparib maintenance significantly improved PFS in the whole population of patients who underwent IDS (median, 14.2 versus 8.2 months, $H R=0.57$, $95 \% \mathrm{CI}=0.441-0.731)$, in the patients who underwent IDS with visible RD (median, 11.1 versus 5.6 months, $\mathrm{HR}=0.41$, $95 \% \mathrm{CI}=0.269-0.620)$ and in those who underwent IDS with no visible $\mathrm{RD}$ (median, 18.2 versus 10.9 months, $\mathrm{HR}=0.65$, 95\% CI=0.461-0.91).

PAOLA-1 trial randomly assigned patients in response after first-line treatment with platinum-taxane $+\mathrm{BEV}$ to 
Table V. PARP inhibitors in first-line therapy of ovarian carcinoma: Randomized trials. Clinical outcome and PARP-I related grade 3-adverse events.

\begin{tabular}{|c|c|c|c|c|c|c|c|c|}
\hline Trial & Arm & PFS median & $\mathrm{HR} 95 \% \mathrm{CI}$ & Anemia & Neutropenia & Thrombocytopenia & Fatigue & Vomiting \\
\hline \multirow[t]{2}{*}{ SOLO-1 } & Olaparib & Not reached & $0.30(0.23-0.41)$ & $22 \%$ & $9 \%$ & $1 \%$ & $4 \%$ & $<1 \%$ \\
\hline & PL & 13.8 & & $2 \%$ & $5 \%$ & $2 \%$ & $2 \%$ & $<1 \%$ \\
\hline \multirow[t]{8}{*}{ PAOLA1 } & Olaparib + BEV & $22.1^{\mathrm{a}}$ & $0.59(0.49-0.72)$ & $17 \%$ & $6 \%$ & $2 \%$ & $5 \%$ & $1 \%$ \\
\hline & $\mathrm{PL}+\mathrm{BEV}$ & 16.6 & & $1 \%$ & $3 \%$ & $<1 \%$ & $1 \%$ & $2 \%$ \\
\hline & Olaparib + BEV & $37.2^{\mathrm{b}}$ & $0.33(0.25-0.45)$ & & & & & \\
\hline & $\mathrm{PL}+\mathrm{BEV}$ & 17.7 & & & & & & \\
\hline & Olaparib + BEV & $28.1^{\mathrm{c}}$ & $0.43(0.28-0.66)$ & & & & & \\
\hline & $\mathrm{PL}+\mathrm{BEV}$ & 16.6 & & & & & & \\
\hline & Olaparib + BEV & $16.6^{\mathrm{d}}$ & $1.00(0.75-1.35)$ & & & & & \\
\hline & $\mathrm{PL}+\mathrm{BEV}$ & 16.2 & & & & & & \\
\hline \multirow[t]{10}{*}{ PRIMA } & Niraparib & $21.9^{\mathrm{e}}$ & $0.43(0.31-0.59)$ & $31 \%$ & $12.8 \%$ & $28.7 \%$ & $1.9 \%$ & $0.8 \%$ \\
\hline & PL & 10.4 & & $1.6 \%$ & $1.2 \%$ & $0.4 \%$ & $0.4 \%$ & $0.8 \%$ \\
\hline & Niraparib & $13.8^{\mathrm{f}}$ & $0.62(0.50-0.76)$ & & & & & \\
\hline & PL & 8.2 & & & & & & \\
\hline & Niraparib & $22.1 \mathrm{~g}$ & $0.40(0.27-0.62)$ & & & & & \\
\hline & PL & 10.9 & & & & & & \\
\hline & Niraparib & $19.6^{\mathrm{h}}$ & $0.50(0.31-0.83)$ & & & & & \\
\hline & PL & 8.2 & & & & & & \\
\hline & Niraparib & $8.1^{\mathrm{i}}$ & $0.68(0.49-0.94)$ & & & & & \\
\hline & PL & 5.4 & & & & & & \\
\hline \multirow[t]{12}{*}{ VELIA } & Vel-throughout & $34.7^{1}$ & $0.44(0.28-0.68)$ & $38 \%$ & $58 \%$ & $28 \%$ & $8 \%$ & $4 \%$ \\
\hline & VEL-combi & 21.1 & $1.22(0.82-1.80)$ & $41 \%$ & $62 \%$ & $31 \%$ & $5 \%$ & $4 \%$ \\
\hline & Control & 22.0 & & $26 \%$ & $49 \%$ & $8 \%$ & $3 \%$ & $2 \%$ \\
\hline & Vel-throughout & $31.9^{\mathrm{m}}$ & $0.57(0.43-0.76)$ & & & & & \\
\hline & VEL-combi & 18.1 & $1.10(0.86-1.41)$ & & & & & \\
\hline & Control & 20.5 & & & & & & \\
\hline & Vel-throughout & $23.5^{\mathrm{n}}$ & $0.68(0.56-0.83)$ & & & & & \\
\hline & VEL-combi & 15.2 & $1.07(0.90-1.29)$ & & & & & \\
\hline & Control & 17.3 & & & & & & \\
\hline & Vel-throughout & $15.0^{\circ}$ & $0.81(0.60-1.09)$ & & & & & \\
\hline & VEL-combi & 12.9 & & & & & & \\
\hline & Control & 11.5 & $1.04(0.78-1.39)$ & & & & & \\
\hline
\end{tabular}

antention to treat population; bHRD tumors including those with BRCA mutation (Preplanned subgroup analysis); ${ }^{\mathrm{C}} \mathrm{HRD}$ tumors without $B R C A$ mutations (Preplanned subgroup analysis); ${ }^{\mathrm{d} H R P}$ tumors (Preplanned subgroup analysis); ${ }^{\mathrm{e}} \mathrm{HRD}$ tumors; fintention to treat population; gHRD tumors including those with $B R C A$ mutation (Preplanned subgroup analysis); hHRD tumors but without $B R C A$ mutations (Preplanned subgroup analysis); ${ }^{i} H R P$ tumors (Preplanned subgroup analysis); ${ }^{1} B R C A$ mutation; mHRD; ${ }^{n}$ intention to treat population; ${ }^{\circ} \mathrm{HRP}$. PFS: Progression-free survival; HR: hazard ratio; 95\%CI: 95\% confidence interval; PL: placebo; BEV: bevacizumab: HRD: homologous recombination deficiency; HRP: homologous recombinant.

receive either olaparib + BEV or placebo + BEV (40). PDS, IDS and no surgery were performed in $50 \%, 42 \%$ and $7 \%$ of the patients in the olaparib + BEV arm and in $51 \%, 41 \%$ and $8 \%$ of those in the placebo + BEV arm. Tumor HRD status was determined by myChoice assay. The analysis of intention to treat population revealed a longer PFS in the olaparib + BEV arm $(\mathrm{HR}=0.59)$. Moreover, preplanned subgroup analysis found that combined maintenance treatment improved PFS both in patients with HRD tumors including those with $B R C A$ mutations $(\mathrm{HR}=0.33)$ and in those with HRD tumors that did not have $B R C A$ mutations $(\mathrm{HR}=0.43$ ) but not in patients with HRP tumors. Hypoxia induced by antiangiogenic treatment could induce down-regulation of $B R C A 1$ and RAD51 and decrease homologous recombination in cancer cells (41-43), and therefore BEV might enhance the activity of olaparib in patients with HRD tumors, and especially in those without BRCA mutations (40). An update of the study showed that olaparib + BEV also significantly improved second progression free survival (PFS2) in the intention to treat population (median, 36.5 versus 32.6 months, $\mathrm{HR}=0.78 ; 95 \% \mathrm{CI}=0.64-0.95)$, in patients with $B R C A$ mutations (median, not reached versus 45 months, $\mathrm{HR}=0.53$ ), in those with HRD tumors (median, 50.3 versus 35 months, $\mathrm{HR}=0.56$ ) and in those with HRD tumors who did not have $B R C A$ mutations (median, 50.3 versus 30.1 months; $\mathrm{HR}=0.60$ ), without no new safety signals (44).

At the ASCO meeting 2021, Pautier et al. (45) reported that olaparib + BEV improved PFS regardless of stage in 
Table VI. PARP inhibitors in first-line therapy of ovarian carcinoma: Ongoing trials.

\begin{tabular}{ll}
\hline NCT04227522: & $\begin{array}{l}\text { Rucaparib maintenance after bevacizumab maintenance following CBDCA-Based first-line } \\
\text { chemotherapy in EOC (MAMOC) }\end{array}$ \\
NCT04532645: & $\begin{array}{l}\text { A pan-European non-interventional, retrospective observational cohort study of pts with BRCA } \\
\text { mutated FIGO stage III-IV ovarian cancer treated with olaparib tablets in the first-line maintenance }\end{array}$ \\
NCT03462212A: & $\begin{array}{l}\text { Randomized, molecular driven phase II trial of CBDCA+PTX+BEV } v \text {. CBDCA + PTX + BEV + } \\
\text { rucaparib } v s . \text { CBDCA + PTX + rucaparib, selected according to HRD status, in pts with advanced } \\
\text { (Stage III B-C-IV) ovarian, primary peritoneal and fallopian tube cancer (MITO 25) }\end{array}$ \\
\hline
\end{tabular}

Table VII. Incorporation of immunotherapy in first-line therapy of ovarian carcinoma: randomized trials

\begin{tabular}{ll}
\hline NCT02718417: & $\begin{array}{l}\text { Randomized, open-label, multicenter, phase } 3 \text { study to evaluate efficacy and safety of avelumab } \\
\text { in combination with and/or following chemotherapy in pts with previously untreated EOC } \\
\text { (JAVELIN OVARIAN 100) }\end{array}$ \\
& A phase III, multicenter, randomized, study of atezolizumab vs. placebo administered in combination \\
NCT03038100: & with PTX+ CBDCA + BEV in pts with newly-diagnosed stage III-IV EOC (IMagyn050) \\
A randomized phase 3, double-blind study of chemotherapy with or without pembrolizumab followed \\
by maintenance with olaparib or placebo for the first-line treatment of $B R C A$ non-mutated advanced \\
epithelial ovarian cancer (EOC) (KEYLYNK-001/ENGOT-ov43 / GOG-3036) \\
A multicenter, randomized, double-blind, placebo- controlled phase 3 study in ovarian cancer \\
patients evaluating rucaparib and nivolumab as maintenance treatment following response to \\
front-line platinum-based chemotherapy (ATHENA)
\end{tabular}

patients with HRD tumors (stage III: median, 39.3 versus 19.9 months, $\mathrm{HR}=0.32,95 \% \mathrm{CI}=0.22-0.47$; stage IV: median, 25.1 versus 12.8 months, $\mathrm{HR}=0.32,95 \% \mathrm{CI}=0.20-0.52$ ). Similarly, the addition of olaparib to BEV maintenance resulted in PFS2 benefit irrespective of stage in the same subgroup of patients (stage III, median: not reached versus 43.0 months, $\mathrm{HR}=0.57,95 \% \mathrm{CI}=0.38-0.87$; stage IV: median, 37.8 versus 25.6 months, $\mathrm{HR}=0.56 ; 95 \% \mathrm{CI}=0.35-0.91$ ).

G3-4 anemia and fatigue were more common in the olaparib + BEV arm, whereas grade 3 hypertension was more frequent in the placebo $+\mathrm{BEV}$ arm (30\% versus $19 \%)$. The incidence of myelodysplastic syndrome, acute myeloid leukemia, or aplastic anemia was $1 \%$ in the olaparib group and $<1 \%$ in the placebo group. The safety profile of olaparib in this trial was consistent with that reported for olaparib in the SOLO-1 trial. On May 2020, FDA approved the combination of olaparib $+\mathrm{BEV}$ for first-line maintenance of HRD-positive advanced ovarian carcinoma.

It is difficult to compare the outcome of the patients enrolled in the SOLO-1 trial and of the patients with $B R C A$ mutations enrolled in PAOLA-1 trial because of the different baseline characteristics and the lack of a common comparator arm. Vergote et al. (46) performed a population adjusted indirect comparison of these trials using a propensity score weighting technique to minimize the differences in the characteristics of the two populations. Two
year-PFS rates were $50 \%$ and $36 \%$, respectively, $(\mathrm{HR}=0.65$, $95 \% \mathrm{CI}=0.43-0.95)$ for the PAOLA-1 BRCA-mutated patients treated with $\mathrm{BEV}+$ placebo and the SOLO-1 patients who received placebo, and $73 \%$ and $50 \% \quad(\mathrm{HR}=0.48$, $95 \% \mathrm{CI}=0.30-0.75)$, respectively, for the SOLO-1 patients treated with olaparib and the PAOLA-1 BRCA- mutated patients treated with $\mathrm{BEV}+$ placebo. On the other hand, the 2-year PFS was not significantly different between the PAOLA-1 BRCA-mutated patients treated with BEV + olaparib and SOLO-1 patients treated with olaparib $(82 \%$ versus $73 \%, \mathrm{HR}=0.71,95 \% \mathrm{CI}=0.45-1.09$ )

The VELIA trial randomized advanced ovarian carcinoma patients to receive PTX + CBDCA plus concomitant and maintenance placebo (control arm), the same chemotherapy plus concomitant veliparib followed by placebo maintenance (veliparib-combination-only), or the same chemotherapy + concomitant veliparib followed by veliparib maintenance (veliparib throughout) (47). The HRD cohort was defined as the patients who had BRCA mutations or HRD tumor at myChoice assay (with a score of $\geq 33$ considered to indicate HRD). According to investigator assessment, the veliparibthroughout arm experienced a longer PFS compared with control arm in the BRCA-mutated cohort $(\mathrm{HR}=0.44, p<0.001)$, in the HRD cohort $(\mathrm{HR}=0.57, p<0.001)$ and in the intention to treat population $(\mathrm{HR}=0.68, p<0.001)$, but not in the HRP cohort. The most common adverse event during treatment in 
the veliparib-throughout arm was nausea (80\%), with most events $(90 \%)$ being of grade 1 or 2 . The incidence of grade 3 4 hematologic toxicity and fatigue are reported in the Table V. One myelodysplastic syndrome developed in the veliparibcombination-only arm, and one acute myeloid leukemia occurred in the veliparib-throughout arm. A supplemental analysis of PFS by blinded independent central reviewers was consistent with the primary investigator assessment (48).

Other studies on the role of PARPi as maintenance therapy after first-line chemotherapy are currently ongoing (Table VI).

The NCT04227522 MAMOC trial is a randomized phase III study including BRCA-non mutated patients with stage III-IV ovarian high-grade serous or high-grade endometrioid or clear cell carcinoma who have undergone BEV maintenance following first-line chemotherapy. After BEV treatment the patients will be randomized to receive either $600 \mathrm{mg}$ rucaparib daily or placebo daily for 12 to 15 months.

NCT04532645 trial is a retrospective, non-interventional, observational cohort study of BRCA-mutated stage III-IV ovarian carcinoma patients treated with olaparib in the first-line maintenance setting in France, Italy, and UK. Physicians will be requested to recruit patients to have their clinical data abstracted from their clinical records in agreement with local laws.

The MITO 25 trial is a randomized, open-label Phase 1-2 study aimed to assess the effect of CBDCA + PTX + BEV (in combination and maintenance) versus $\mathrm{CBDCA}+\mathrm{PTX}+\mathrm{BEV}$ + Rucaparib (Rucaparib only in maintenance) versus CBDCA + PTX + Rucaparib (Rucaparib only in maintenance) on PFS of patients with advanced high grade ovarian carcinoma treated according to HRD status.

\section{Trials With Immunotherapy}

Up to now literature data suggest that the immune checkpoint inhibitors avelumab and atezolizumab have limited impact on the clinical outcome of patients with newly diagnosed ovarian carcinoma $(49,50)$ (Table VII).

The phase III NCT02718417 JAVELIN Ovarian 100 trial randomized 998 patients with stage III-IV ovarian carcinoma (after PDS or candidates to NACT) to receive PTX (175 $\mathrm{mg} / \mathrm{m}^{2} \mathrm{Q} 3 \mathrm{~W}$ or $80 \mathrm{mg} / \mathrm{m}^{2}$ weekly) + CBDCA AUC5-6 Q3W for 6 cycles followed by avelumab maintenance $[10 \mathrm{mg} / \mathrm{kg}$ every 2 weeks (Q2W)] or the same chemotherapy concomitant with avelumab (10 mg/kg Q3W) followed by avelumab Q2W maintenance, or the same chemotherapy followed by observation (control arm) (49). At interim analysis PFS of both avelumab arms was not improved compared with the control arm, and the trial was stopped early.

The phase III trial NCT03038100 IMagyn050 randomly assigned 1301 stage III-IV ovarian carcinoma patients (with either macroscopic RD after PDS or candidates for NACT) to receive either atezolizumab (1,200 $\mathrm{mg}$ Q3W, cycles 1-22) or placebo (Q3W, cycles 1-22) combined with PTX $\left(175 \mathrm{mg} / \mathrm{m}^{2}\right.$
Q3W, cycles 1-6) + CBDCA (AUC 6 Q3W cycles 1-6) + BEV (15 mg/kg Q3W, cycles 2-22) (50). Programmed death-ligand 1 (PD-L1) status [PD-L1-expressing immune cells (ICs) as percentage of tumor in $<1 \%$ versus $\geq 1 \%$ (PD-L1-positive)] was assessed with immunohistochemistry (VENTANA). Atezolizumab failed to improve PFS both in intention to treat population and in patients with PD-L1-positive tumors. However, in a prespecified exploratory analysis with a threshold of PD-L1 IC $\geq 5 \%$ (representing $20 \%$ of the intention to treat population in the IMagyn050 trial), PFS was better in atezolizumab arm (median, not reached versus 20.2 months, $\mathrm{HR}=0.64$, 95\% $\mathrm{CI}=0.43-0.96)$. However, some trials investigating other immunotherapies in first-line treatment of advanced ovarian carcinoma are currently ongoing.

The purpose of the NCT03740165 ENGOT-ov43 trial is to assess the efficacy and safety of PTX + CBDCA \pm pembrolizumab and maintenance olaparib in patients without $B R C A$ mutations. Following a lead-in period during which all participants receive a single Q3W cycle of PTX + CBDCA, the patients are randomly assigned to chemotherapy + pembrolizumab followed by olaparib maintenance, chemotherapy + pembrolizumab followed by placebo maintenance or chemotherapy + placebo followed by placebo maintenance. All participants can also receive BEV on Day 1 of each Q3W cycle at investigator's discretion.

The NCT03522246 ATHENA, double-blind, dual placebocontrolled, 4-arm study is evaluating rucaparib and nivolumab as maintenance treatment following response to first-line chemotherapy. Response to treatment will be assessed according to HRD status. The 3 experimental arms are represented by rucaparib + nivolumab, rucaparib + intravenous placebo, oral placebo + nivolumab, whereas the control arm consists of oral placebo + intravenous placebo.

The NCT03275506A GINECO phase II trial randomized in a ratio 2:1 91 patients with unresectable stage IIIC-IV high-grade serous ovarian carcinoma to receive 4 cycles of PTX + CBDCA with or without pembrolizumab (51). Eighty of these patients also received BEV concurrently with chemotherapy and sequentially as maintenance with or without pembrolizumab. Complete resection at IDS was obtained in $71 \%$ and $58 \%$ of the patients treated with and without pembrolizumab, respectively. Survival data and translational research including PD-L1 status are ongoing to better define the role of pembrolizumab as treatment option in this clinical setting.

Gemogenovatucel-T is an autologous tumor cell vaccine obtained from harvested tumor tissue and genetically modified to express the granulocyte macrophage colony stimulating factor (GM-CSF) and to block the production of trasforming growth factor (TGF) TGF- $\beta 2$ (52). NCT02346747 is a doubleblind, placebo-controlled, phase $2 \mathrm{~b}$ trial comparing this immunotherapy versus placebo as maintenance treatment in patients with advanced ovarian high-grade serous, endometrioid 
or clear cell carcinoma in complete response after PDS and 58 cycles of PTX/CBDCA-based chemotherapy. Vaccine or placebo was administered intradermally every month for 4-12 doses (53). The preliminary assessment of 135 patients showed that the vaccine was associated with a trend to a better PFS $(\mathrm{HR}=0.69,90 \% \mathrm{CI}=0.44-1.07)$ in the whole population and a significantly better PFS in $B R C A$-wild type patients (HR=0.51, $90 \% \mathrm{CI}=0.30-0.88)$. At a post-hoc analysis Gemogenovatucel significantly improved PFS ( $\mathrm{HR}=0.386,90 \% \mathrm{CI}=0.199-0.750)$ and $\mathrm{OS}(\mathrm{HR}=0.342,90 \% \mathrm{CI}=0.141-0.832)$ in patients with HRP based on myChoice assay (score <42) (54).

\section{Conclusion}

The patients start chemotherapy with the first cycle of PTX $\left(175 \mathrm{mg} / \mathrm{m}^{2}\right)+$ CBDCA (AUC5) Q3W regimen. The results of $B R C A$ testing on tissue samples collected at PDS or laparoscopy or diagnostic imaging techniques guided biopsies should be available before the second cycle of chemotherapy. If $B R C A$ is mutated, 5 cycles of PTX/CBDCA are administered and followed by olaparib maintenance in responsive cases according to SOLO-1 trial. Niraparib maintenance may represent an alternative option to olaparib maintenance. If $B R C A$ is wild-type, the clinical behavior depends on both the availability of HRD assay as well as by the presence or lack of risk factors for BEV-related adverse events. These are represented by uncontrolled hypertension, clinically significant, cardiovascular disease, non-healing wound, thrombotic or hemorrhagic disorders (including cerebrovascular accident/stroke or transient ischemic attack or sub-arachnoid haemorrhage), signs or symptoms of gastrointestinal obstruction or history of abdominal fistula, gastrointestinal perforation, or intra-abdominal abscess within the preceding 6 months.

\section{HRD assay not available.}

i) No contraindications to BEV: $\mathrm{BEV}$ can be added concurrently to PTX/CBDCA and then sequentially as maintenance therapy according to GOG 218 trial. Patients who undergo IDS omit both perioperative cycles of BEV.

ii) Contraindications to BEV: PTX/CBDCA regimen is continued and then followed by niraparib maintenance in responsive cases, especially in patients with stage III disease with visible RD after PDS, inoperable stage III disease, stage IV disease and in patients who had received NACT. In the PRIMA trial niraparib has offered a median absolute PFS benefit of 5.6 months $(\mathrm{HR}=0.62)$ compared with placebo in the intention to treat population.

\section{HRD assay positive}

i) No contraindications to BEV: $\mathrm{BEV}$ can be added concurrently to PTX/CBDCA and then sequentially and olaparib can be added as maintenance therapy in responsive cases according to the PAOLA-1 trial. Patients who undergo IDS omit both perioperative cycles of BEV. In the PAOLA1 study olaparib + BEV has been associated with a median absolute PFS advantage of 11.5 months $(\mathrm{HR}=0.43)$ versus placebo $+\mathrm{BEV}$ in patients with HRD tumor and $B R C A$-wt. ii) Contraindications to BEV: PTX/CBDCA regimen is continued and then followed by niraparib maintenance in responsive cases, especially in patients with stage III disease with visible RD after PDS, inoperable stage III disease, stage IV disease and in patients who had received NACT. In the PRIMA trial niraparib has given an absolute median PFS benefit of 11.4 months $(\mathrm{HR}=0.50)$ compared with placebo in patients with HRD tumor and $B R C A$-wt.

HRD test negative.

i) No contraindications to BEV: $\mathrm{BEV}$ can be added concurrently to PTX/CBDCA and then sequentially as maintenance therapy according to the GOG218 trial. Patients who undergo IDS omit both perioperative cycles of BEV.

i) Contraindications to BEV: PTX/CBDCA regimen is continued and eventually followed by niraparib maintenance in responsive cases especially in patients with stage III disease with visible RD after PDS, inoperable stage III disease, stage IV disease and in patients who had received NACT. In the PRIMA trial niraparib has significantly improved PFS $(H R=0.68)$ compared with placebo in patients with HRP tumor, with an absolute median PFS benefit of only 2.7 months.

The role of immunotherapy in first-line treatment of newly diagnosed ovarian carcinoma is still investigational.

\section{Conflicts of Interest}

The Authors declare no conflicts of interest in relation to this study.

\section{Authors' Contributions}

Conceptualization, Writing - original draft: Angiolo Gadducci; Data curation, formal analysis, methodology, writing, review and editing: Angiolo Gadducci and Stefania Cosio.

\section{References}

1 Bray F, Ferlay J, Soerjomataram I, Siegel RL, Torre LA and Jemal A: Global cancer statistics 2018: GLOBOCAN estimates of incidence and mortality worldwide for 36 cancers in 185 countries. CA Cancer J Clin 68(6): 394-424, 2018. PMID: 30207593. DOI: $10.3322 /$ caac. 21492

2 Kurman RJ and Shih IeM: The dualistic model of ovarian carcinogenesis: Revisited, revised, and expanded. Am J Pathol 186(4): 733-747, 2016. PMID: 27012190. DOI: 10.1016/ j.ajpath.2015.11.011

3 Prat J, D'Angelo E and Espinosa I: Ovarian carcinomas: at least five different diseases with distinct histological features and molecular genetics. Hum Pathol 80: 11-27, 2018. PMID: 29944973. DOI: 10.1016/j.humpath.2018.06.018 
4 Colombo N, Sessa C, du Bois A, Ledermann J, McCluggage WG, McNeish I, Morice P, Pignata S, Ray-Coquard I, Vergote I, Baert T, Belaroussi I, Dashora A, Olbrecht S, Planchamp F, Querleu D and ESMO-ESGO Ovarian Cancer Consensus Conference Working Group: ESMO-ESGO consensus conference recommendations on ovarian cancer: pathology and molecular biology, early and advanced stages, borderline tumours and recurrent disease $\dagger$. Ann Oncol 30(5): 672-705, 2019. PMID: 31046081. DOI: 10.1093/annonc/mdz062

5 Aletti GD, Eisenhauer EL, Santillan A, Axtell A, Aletti G, Holschneider C, Chi DS, Bristow RE and Cliby WA: Identification of patient groups at highest risk from traditional approach to ovarian cancer treatment. Gynecol Oncol 120(1): 23-28, 2011. PMID: 20933255. DOI: 10.1016/j.ygyno.2010.09.010

6 Wright AA, Bohlke K, Armstrong DK, Bookman MA, Cliby WA, Coleman RL, Dizon DS, Kash JJ, Meyer LA, Moore KN, Olawaiye AB, Oldham J, Salani R, Sparacio D, Tew WP, Vergote I and Edelson MI: Neoadjuvant chemotherapy for newly diagnosed, advanced ovarian cancer: Society of Gynecologic Oncology and American Society of Clinical Oncology Clinical Practice Guideline. Gynecol Oncol 143(1): 3-15, 2016. PMID: 27650684. DOI: 10.1016/j.ygyno.2016.05.022

7 Armstrong DK, Alvarez RD, Bakkum-Gamez JN, Barroilhet L, Behbakht K, Berchuck A, Berek JS, Chen LM, Cristea M, DeRosa M, ElNaggar AC, Gershenson DM, Gray HJ, Hakam A, Jain A, Johnston C, Leath CA III, Liu J, Mahdi H, Matei D, McHale M, McLean K, O’Malley DM, Penson RT, Percac-Lima S, Ratner E, Remmenga SW, Sabbatini P, Werner TL, Zsiros E, Burns JL and Engh AM: NCCN guidelines insights: Ovarian cancer, Version 1.2019. J Natl Compr Canc Netw 17(8): 896909, 2019. PMID: 31390583. DOI: 10.6004/jnccn.2019.0039

8 McGuire WP, Hoskins WJ, Brady MF, Kucera PR, Partridge EE, Look KY, Clarke-Pearson DL and Davidson M: Cyclophosphamide and cisplatin compared with paclitaxel and cisplatin in patients with stage III and stage IV ovarian cancer. $\mathrm{N}$ Engl J Med 334(1): 1-6, 1996. PMID: 7494563. DOI: 10.1056/NEJM199601043340101

9 Piccart MJ, Bertelsen K, James K, Cassidy J, Mangioni C, Simonsen E, Stuart G, Kaye S, Vergote I, Blom R, Grimshaw R, Atkinson RJ, Swenerton KD, Trope C, Nardi M, Kaern J, Tumolo S, Timmers P, Roy JA, Lhoas F, Lindvall B, Bacon M, Birt A, Andersen JE, Zee B, Paul J, Baron B and Pecorelli S: Randomized intergroup trial of cisplatin-paclitaxel versus cisplatin-cyclophosphamide in women with advanced epithelial ovarian cancer: three-year results. J Natl Cancer Inst 92(9): 699708, 2000. PMID: 10793106. DOI: 10.1093/jnci/92.9.699

10 Neijt JP, Engelholm SA, Tuxen MK, Sorensen PG, Hansen M, Sessa C, de Swart CA, Hirsch FR, Lund B and van Houwelingen HC: Exploratory phase III study of paclitaxel and cisplatin versus paclitaxel and carboplatin in advanced ovarian cancer. J Clin Oncol 18(17): 3084-3092, 2000. PMID: 10963636. DOI: 10.1200/JCO.2000.18.17.3084

11 Muggia FM, Braly PS, Brady MF, Sutton G, Niemann TH, Lentz SL, Alvarez RD, Kucera PR and Small JM: Phase III randomized study of cisplatin versus paclitaxel versus cisplatin and paclitaxel in patients with suboptimal stage III or IV ovarian cancer: a gynecologic oncology group study. J Clin Oncol 18(1): 106-115, 2000. PMID: 10623700. DOI: 10.1200/JCO.2000.18.1.106

12 Ozols RF, Bundy BN, Greer BE, Fowler JM, Clarke-Pearson D, Burger RA, Mannel RS, DeGeest K, Hartenbach EM, Baergen
R and Gynecologic Oncology Group: Phase III trial of carboplatin and paclitaxel compared with cisplatin and paclitaxel in patients with optimally resected stage III ovarian cancer: a Gynecologic Oncology Group study. J Clin Oncol 21(17): 31943200, 2003. PMID: 12860964. DOI: 10.1200/JCO.2003.02.153

13 du Bois A, Lück HJ, Meier W, Adams HP, Möbus V, Costa S, Bauknecht T, Richter B, Warm M, Schröder W, Olbricht S, Nitz U, Jackisch C, Emons G, Wagner U, Kuhn W, Pfisterer J and Arbeitsgemeinschaft Gynäkologische Onkologie Ovarian Cancer Study Group: A randomized clinical trial of cisplatin/paclitaxel versus carboplatin/paclitaxel as first-line treatment of ovarian cancer. J Natl Cancer Inst 95(17): 1320-1329, 2003. PMID: 12953086. DOI: $10.1093 /$ jnci/djg036

14 Gadducci A, Cosio S, Conte PF and Genazzani AR: Consolidation and maintenance treatments for patients with advanced epithelial ovarian cancer in complete response after first-line chemotherapy: a review of the literature. Crit Rev Oncol Hematol 55(2): 153-166, 2005. PMID: 15890524. DOI: 10.1016/j.critrevonc.2005.03.003

15 Pfisterer J, Weber B, Reuss A, Kimmig R, du Bois A, Wagner U, Bourgeois H, Meier W, Costa S, Blohmer JU, Lortholary A, Olbricht S, Stähle A, Jackisch C, Hardy-Bessard AC, Möbus V, Quaas J, Richter B, Schröder W, Geay JF, Lück HJ, Kuhn W, Meden H, Nitz U, Pujade-Lauraine E, AGO-OVAR. and GINECO: Randomized phase III trial of topotecan following carboplatin and paclitaxel in first-line treatment of advanced ovarian cancer: a gynecologic cancer intergroup trial of the AGO-OVAR and GINECO. J Natl Cancer Inst 98(15): 10361045, 2006. PMID: 16882940. DOI: 10.1093/jnci/djj296

16 Bookman MA, Brady MF, McGuire WP, Harper PG, Alberts DS, Friedlander M, Colombo N, Fowler JM, Argenta PA, De Geest K, Mutch DG, Burger RA, Swart AM, Trimble EL, Accario-Winslow $\mathrm{C}$ and Roth LM: Evaluation of new platinum-based treatment regimens in advanced-stage ovarian cancer: a Phase III Trial of the Gynecologic Cancer Intergroup. J Clin Oncol 27(9): 1419-1425, 2009. PMID: 19224846. DOI: 10.1200/JCO.2008.19.1684

17 Pecorelli S, Favalli G, Gadducci A, Katsaros D, Panici PB, Carpi A, Scambia G, Ballardini M, Nanni O, Conte P and After 6 Italian Cooperative Group: Phase III trial of observation versus six courses of paclitaxel in patients with advanced epithelial ovarian cancer in complete response after six courses of paclitaxel/platinum-based chemotherapy: final results of the After-6 protocol 1. J Clin Oncol 27(28): 4642-4648, 2009. PMID: 19704064. DOI: 10.1200/JCO.2009.21.9691

18 Bookman MA, Brady MF, McGuire WP, Harper PG, Alberts DS, Friedlander M, Colombo N, Fowler JM, Argenta PA, De Geest K, Mutch DG, Burger RA, Swart AM, Trimble EL, Accario-Winslow $\mathrm{C}$ and Roth LM: Evaluation of new platinum-based treatment regimens in advanced-stage ovarian cancer: a Phase III Trial of the Gynecologic Cancer Intergroup. J Clin Oncol 27(9): 14191425, 2009. PMID: 19224846. DOI: 10.1200/JCO.2008.19.1684

19 Bolis G, Scarfone G, Raspagliesi F, Mangili G, Danese S, Scollo P, Lo Russo D, Villa A, Aimone PD and Scambia G: Paclitaxel/carboplatin versus topotecan/paclitaxel/carboplatin in patients with FIGO suboptimally resected stage III-IV epithelial ovarian cancer a multicenter, randomized study. Eur J Cancer 46(16): 2905-2912, 2010. PMID: 20673626. DOI: 10.1016/j.ejca. 2010.06.124

20 Burger RA, Brady MF, Bookman MA, Fleming GF, Monk BJ, Huang H, Mannel RS, Homesley HD, Fowler J, Greer BE, 
Boente M, Birrer MJ, Liang SX and Gynecologic Oncology Group: Incorporation of bevacizumab in the primary treatment of ovarian cancer. N Engl J Med 365(26): 2473-2483, 2011. PMID: 22204724. DOI: 10.1056/NEJMoa1104390

21 Tewari KS, Burger RA, Enserro D, Norquist BM, Swisher EM, Brady MF, Bookman MA, Fleming GF, Huang H, Homesley HD, Fowler JM, Greer BE, Boente M, Liang SX, Ye C, Bais C, Randall LM, Chan JK, Ferriss JS, Coleman RL, Aghajanian C, Herzog TJ, DiSaia PJ, Copeland LJ, Mannel RS, Birrer MJ and Monk BJ: Final overall survival of a randomized trial of bevacizumab for primary treatment of ovarian cancer. J Clin Oncol 37(26): 2317-2328, 2019. PMID: 31216226. DOI: 10.1200/JCO.19.01009

22 Perren TJ, Swart AM, Pfisterer J, Ledermann JA, PujadeLauraine E, Kristensen G, Carey MS, Beale P, Cervantes A, Kurzeder C, du Bois A, Sehouli J, Kimmig R, Stähle A, Collinson F, Essapen S, Gourley C, Lortholary A, Selle F, Mirza MR, Leminen A, Plante M, Stark D, Qian W, Parmar MK, Oza AM and ICON7 Investigators: A phase 3 trial of bevacizumab in ovarian cancer. N Engl J Med 365(26): 2484-2496, 2011. PMID: 22204725. DOI: 10.1056/NEJMoa1103799

23 Oza AM, Cook AD, Pfisterer J, Embleton A, Ledermann JA, Pujade-Lauraine E, Kristensen G, Carey MS, Beale P, Cervantes A, Park-Simon TW, Rustin G, Joly F, Mirza MR, Plante M, Quinn M, Poveda A, Jayson GC, Stark D, Swart AM, Farrelly L, Kaplan $\mathrm{R}$, Parmar MK, Perren TJ and ICON7 trial investigators: Standard chemotherapy with or without bevacizumab for women with newly diagnosed ovarian cancer (ICON7): overall survival results of a phase 3 randomised trial. Lancet Oncol 16(8): 928-936, 2015. PMID: 26115797. DOI: 10.1016/S1470-2045(15)00086-8

24 González Martín A, Oza AM, Embleton AC, Pfisterer J, Ledermann JA, Pujade-Lauraine E, Kristensen G, Bertrand MA, Beale P, Cervantes A, Kent E, Kaplan RS, Parmar MKB, Scotto N, Perren TJ and ICON7 investigators: Exploratory outcome analyses according to stage and/or residual disease in the ICON7 trial of carboplatin and paclitaxel with or without bevacizumab for newly diagnosed ovarian cancer. Gynecol Oncol 152(1): 5360, 2019. PMID: 30449719. DOI: 10.1016/j.ygyno.2018.08.036

25 An observational study of avastin (bevacizumab) in combination with carboplatin/paclitaxel in first line in patients with advanced epithelial ovarian fallopian tube or primary peritoneal cancer (OTILIA) (ClinicalTrials.gov Identifier: NCT01697488). Available at: https://clinicaltrials.gov/ct2/show/NCT01697488 [Last accessed on February 1, 2020]

26 Hall M, Bertelli G, Li L, Green C, Chan S, Yeoh CC, Hasan J, Jones R, Ograbek A and Perren TJ: Role of front-line bevacizumab in advanced ovarian cancer: the OSCAR study. Int J Gynecol Cancer 30(2): 213-220, 2020. PMID: 31780570. DOI: 10.1136/ijgc-2019-000512

27 Komiyama S, Kato K, Inokuchi Y, Takano H, Matsumoto T, Hongo A, Asai-Sato M, Arakawa A, Kamiura S, Tabata T, Takeshima $\mathrm{N}$ and Sugiyama T: Bevacizumab combined with platinum-taxane chemotherapy as first-line treatment for advanced ovarian cancer: a prospective observational study of safety and efficacy in Japanese patients (JGOG3022 trial). Int J Clin Oncol 24(1): 103-114, 2019. PMID: 30030657. DOI: 10.1007/s10147-018-1319-y

28 Wu PY, Cheng YM, Shen MR, Chen YC, Huang YF and Chou CY: Real-world study of adding bevacizumab to chemotherapy for ovarian, tubal, and peritoneal cancer as front-line or relapse therapy (ROBOT): 8-year experience. Front Oncol 10: 1095, 2020. PMID: 32760668. DOI: 10.3389/fonc.2020.01095

29 Oza AM, Selle F, Davidenko I, Korach J, Mendiola C, Pautier P, Chmielowska E, Bamias A, DeCensi A, Zvirbule Z, GonzálezMartín A, Hegg R, Joly F, Zamagni C, Gadducci A, Martin N, Robb S and Colombo N: Efficacy and safety of bevacizumabcontaining therapy in newly diagnosed ovarian cancer: ROSiA single-arm phase 3B study. Int J Gynecol Cancer 27(1): 50-58, 2017. PMID: 27749456. DOI: 10.1097/IGC.0000000000000836

30 Sugiyama T, Okamoto A, Enomoto T, Hamano T, Aotani E, Terao Y, Suzuki N, Mikami M, Yaegashi N, Kato K, Yoshikawa H, Yokoyama Y, Tanabe H, Nishino K, Nomura H, Kim JW, Kim BG, Pignata S, Alexandre J, Green J, Isonishi S, Terauchi F, Fujiwara K and Aoki D: Randomized phase III trial of irinotecan plus cisplatin compared with paclitaxel plus carboplatin as firstline chemotherapy for ovarian clear cell carcinoma: JGOG3017/GCIG trial. J Clin Oncol 34(24): 2881-2887, 2016. PMID: 27400948. DOI: 10.1200/JCO.2016.66.9010

31 Daniele G, Raspagliesi F, Scambia G, Pisano C, Colombo N, Frezzini S, Tognon G, Artioli G, Gadducci A, Lauria R, Ferrero A, Cinieri S, De Censi A, Breda E, Scollo P, De Giorgi U, Lissoni AA, Katsaros D, Lorusso D, Salutari V, Cecere SC, Zaccarelli E, Nardin M, Bogani G, Distefano M, Greggi S, Piccirillo MC, Fossati R, Giannone G, Arenare L, Gallo C, Perrone F and Pignata S: Bevacizumab, carboplatin, and paclitaxel in the first line treatment of advanced ovarian cancer patients: the phase IV MITO16A/MaNGO-OV2A study. Int J Gynecol Cancer 31(6): 875-882, 2021. PMID: 33931498. DOI: 10.1136/ijgc-2021-002434

32 Pfisterer J, Joly F, Kristensen G, Rau J, Mahner S, Pautier P, Elbalat A, Kurtz J, Canzler U, Sehouli J, Heubner M, Hartkopf A, Baumann K, Hasenburg A, Hanker L, Belau A, Schmalfeldt B, Denschlag D, Park-simon T and Harter P: Optimal treatment duration of bevacizumab (BEV) combined with carboplatin and paclitaxel in patients (pts) with primary epithelial ovarian (EOC), fallopian tube (FTC) or peritoneal cancer (PPC): A multicenter open-label randomized 2-arm phase 3 ENGOT/GCIG trial of the AGO Study Group, GINECO, and NSGO (AGO-OVAR 17/BOOST, GINECO OV118, ENGOT Ov-15, NCT01462890). Journal of Clinical Oncology 39(15 suppl): 5501-5501, 2021. DOI: 10.1200/JCO.2021.39.15_suppl.5501

33 Rouzier R, Gouy S, Selle F, Lambaudie E, Floquet A, Fourchotte V, Pomel C, Colombo PE, Kalbacher E, Martin-Francoise S, Fauvet R, Follana P, Lesoin A, Lecuru F, Ghazi Y, Dupin J, Chereau E, Zohar S, Cottu P and Joly F: Efficacy and safety of bevacizumab-containing neoadjuvant therapy followed by interval debulking surgery in advanced ovarian cancer: Results from the ANTHALYA trial. Eur J Cancer 70: 133-142, 2017. PMID: 27914243. DOI: 10.1016/j.ejca.2016.09.036

34 Vergote I, Tropé CG, Amant F, Kristensen GB, Ehlen T, Johnson $\mathrm{N}$, Verheijen RH, van der Burg ME, Lacave AJ, Panici PB, Kenter GG, Casado A, Mendiola C, Coens C, Verleye L, Stuart GC, Pecorelli S, Reed NS, European Organization for Research and Treatment of Cancer-Gynaecological Cancer Group and NCIC Clinical Trials Group: Neoadjuvant chemotherapy or primary surgery in stage IIIC or IV ovarian cancer. N Engl J Med 363(10): 943-953, 2010. PMID: 20818904. DOI: 10.1056/ NEJMoa0908806

35 Moore K, Colombo N, Scambia G, Kim BG, Oaknin A, Friedlander M, Lisyanskaya A, Floquet A, Leary A, Sonke GS, Gourley C, Banerjee S, Oza A, González-Martín A, Aghajanian 
C, Bradley W, Mathews C, Liu J, Lowe ES, Bloomfield R and DiSilvestro P: Maintenance olaparib in patients with newly diagnosed advanced ovarian cancer. N Engl J Med 379(26): 24952505, 2018. PMID: 30345884. DOI: 10.1056/NEJMoa1810858

36 Banerjee S, Moore K, Colombo N, Scambia G, Kim B, Oaknin A, Friedlander M, Lisyanskaya A, Floquet A, Leary A, Sonke G, Gourley C, Oza A, González-Martín A, Aghajanian C, Bradley W, Holmes E, Lowe E and Disilvestro P: 811MO Maintenance olaparib for patients (pts) with newly diagnosed, advanced ovarian cancer (OC) and a BRCA mutation (BRCAm): 5-year (y) follow-up (f/u) from SOLO1. Annals of Oncology 31: S613, 2021. DOI: 10.1016/j.annonc.2020.08.950

37 DiSilvestro P, Colombo N, Scambia G, Kim BG, Oaknin A, Friedlander M, Lisyanskaya A, Floquet A, Leary A, Sonke GS, Gourley C, Banerjee S, Oza A, González-Martín A, Aghajanian CA, Bradley WH, Mathews CA, Liu J, Lowe ES, Bloomfield R and Moore KN: Efficacy of maintenance olaparib for patients with newly diagnosed advanced ovarian cancer with a BRCA mutation: Subgroup analysis findings from the SOLO1 trial. J Clin Oncol 38(30): 3528-3537, 2020. PMID: 32749942. DOI: 10.1200/JCO.20.00799

38 Friedlander M, Moore KN, Colombo N, Scambia G, Kim BG, Oaknin A, Lisyanskaya A, Sonke GS, Gourley C, Banerjee S, Oza A, González-Martín A, Aghajanian C, Bradley WH, Liu J, Mathews C, Selle F, Lortholary A, Lowe ES, Hettle R, Flood E, Parkhomenko E and DiSilvestro P: Patient-centred outcomes and effect of disease progression on health status in patients with newly diagnosed advanced ovarian cancer and a BRCA mutation receiving maintenance olaparib or placebo (SOLO1): a randomised, phase 3 trial. Lancet Oncol 22(5): 632-642, 2021. PMID: 33862001. DOI: 10.1016/S1470-2045(21)00098-X

39 González-Martín A, Pothuri B, Vergote I, DePont Christensen R, Graybill W, Mirza MR, McCormick C, Lorusso D, Hoskins P, Freyer G, Baumann K, Jardon K, Redondo A, Moore RG, Vulsteke C, O'Cearbhaill RE, Lund B, Backes F, Barretina-Ginesta P, Haggerty AF, Rubio-Pérez MJ, Shahin MS, Mangili G, Bradley WH, Bruchim I, Sun K, Malinowska IA, Li Y, Gupta D, Monk BJ and PRIMA/ENGOT-OV26/GOG-3012 Investigators: Niraparib in patients with newly diagnosed advanced ovarian cancer. N Engl J Med 381(25): 2391-2402, 2019. PMID: 31562799. DOI: 10.1056/NEJMoa1910962

40 Ray-Coquard, I, Pautier, P, Pignata, S, Pérol D, González-Martín A, Berger R, Fujiwara K, Vergote I, Colombo N, Mäenpää J, Selle F, Sehouli J, Lorusso D, Guerra Alía EM, Reinthaller A, Nagao S, Lefeuvre-Plesse C, Canzler U, Scambia G, Lortholary A, Marmé F, Combe P, de Gregorio N, Rodrigues M, Buderath P, Dubot C, Burges A, You B, Pujade-Lauraine E and Harter P: Olaparib plus bevacizumab as first-line maintenance in ovarian cancer. N Engl J Med 381: 2416-2428, 2019. PMID: 31851799. DOI: $10.1056 /$ NEJMoa1911361

41 Bindra RS, Schaffer PJ, Meng A, Woo J, Måseide K, Roth ME, Lizardi P, Hedley DW, Bristow RG and Glazer PM: Downregulation of Rad51 and decreased homologous recombination in hypoxic cancer cells. Mol Cell Biol 24(19): 8504-8518, 2004. PMID: 15367671. DOI: 10.1128/MCB.24.19.8504-8518.2004

42 Bindra RS, Gibson SL, Meng A, Westermark U, Jasin M, Pierce AJ, Bristow RG, Classon MK and Glazer PM: Hypoxia-induced down-regulation of BRCA1 expression by E2Fs. Cancer Res 65(24): 11597-11604, 2005. PMID: 16357170. DOI: 10.1158/ 0008-5472.CAN-05-2119
43 Gadducci A and Guerrieri ME: PARP inhibitors alone and in combination with other biological agents in homologous recombination deficient epithelial ovarian cancer: From the basic research to the clinic. Crit Rev Oncol Hematol 114: 153-165, 2017. PMID: 28477743. DOI: 10.1016/j.critrevonc.2017.04.006

44 González Martín A, Taz Y, Heitz F, Montane L, Gargiulo P, Berger R, Yonemori K, Vergote I, Bologna A, Maenpaa J, Costan C, Canzler U, Zamagni C, Guerra-Alia EM, Levaché CB, Marmé F, Kalbacher E, De Gregorio N, Dohollou N and RayCoquard IL: Maintenance olaparib plus bevacizumab (bev) in patients (pts)with newly diagnosed advanced high-grade ovarian carcinoma (HGOC): Final analysis of second progression-free survival (PFS2) in the phase III PAOLA-1/ENGOT-ov25 trial. Ann Oncol 31(suppl 4): S1163-S1164, 2021. DOI: 10.1016/ j.annonc.2020.08.2263

45 Pautier P, Harter P, Pisano C, Cropet C, Hernando polo S, Berger R, Matsumoto T, Vergote I, Colombo N, Noettrup T, Garnier G, Hillemanns P, Zamagni C, Gonzalez martin A, Lefeuvre-plesse C, Denschlag D, Lortholary A, Sehouli J, Selle F and Raycoquard I: Progression-free survival (PFS) and second PFS (PFS2) by disease stage in patients (pts) with homologous recombination deficiency (HRD)-positive newly diagnosed advanced ovarian cancer receiving bevacizumab (bev) with olaparib/placebo maintenance in the phase III PAOLA1/ENGOT-ov25 trial. Journal of Clinical Oncology 39(15 suppl): 5514-5514, 2021. DOI: 10.1200/JCO.2021.39.15_suppl.5514

46 Vergote I, Moore K, Hettle R, Rhodes K, Ouwens M and Raycoquard I: Population adjusted indirect comparison of the SOLO1 and PAOLA-1/ENGOT-ov25 studies of olaparib with or without bevacizumab, bev alone and placebo in the maintenance treatment of women with newly diagnosed stage III/IV ovarian cancer with BRCA mutation. Gynecologic Oncology 159: 19-20, 2020. DOI: 10.1016/j.ygyno.2020.06.038

47 Coleman RL, Fleming GF, Brady MF, Swisher EM, Steffensen KD, Friedlander M, Okamoto A, Moore KN, Efrat Ben-Baruch N, Werner TL, Cloven NG, Oaknin A, DiSilvestro PA, Morgan MA, Nam JH, Leath CA 3rd, Nicum S, Hagemann AR, Littell RD, Cella D, Baron-Hay S, Garcia-Donas J, Mizuno M, BellMcGuinn K, Sullivan DM, Bach BA, Bhattacharya S, Ratajczak CK, Ansell PJ, Dinh MH, Aghajanian C and Bookman MA: Veliparib with first-line chemotherapy and as maintenance therapy in ovarian cancer. N Engl J Med 381(25): 2403-2415, 2019. PMID: 31562800 . DOI: 10.1056/NEJMoa 1909707

48 Aghajanian C, Bookman MA, Fleming GF, Swisher EM, Steffensen KD, Friedlander M, Okamoto A, Jackson CG, Sullivan D, Ratajczak CK and Coleman RL: Progression-free survival by investigator versus blinded independent central review in newly diagnosed patients with high-grade serous ovarian cancer: Analysis of the VELIA/GOG-3005 trial. Gynecol Oncol 162(2): 375-381, 2021. PMID: 34112513. DOI: 10.1016/j. ygyno.2021.05.031

49 Ledermann JA, Colombo N, Oza AM, Keiichi Fujiwara K, Birrer M, Randall LM, Poddubskaya EV, Scambia G, Shparyk YV, Lim MC, Bhoola SM, Sohn J, Yonemori K, Stewart RA, Zhang X, Zohren F, Linn C and Monk BJ: Avelumab in combination with and/or following chemotherapy vs chemotherapy alone in patients with previously untreated epithelial ovarian cancer: Results from the phase 3 JAVELIN Ovarian 100 trial. Gynecol Oncol 159(suppl 1): 13-14, 2020. DOI: $10.1016 /$ j.ygyno.2020.06.025 
50 Moore KN, Bookman M, Sehouli J, Miller A, Anderson C, Scambia G, Myers T, Taskiran C, Robison K, Mäenpää J, Willmott L, Colombo N, Thomes-Pepin J, Liontos M, Gold MA, Garcia Y, Sharma SK, Darus CJ, Aghajanian C, Okamoto A, Wu X, Safin R, Wu F, Molinero L, Maiya V, Khor VK, Lin YG and Pignata S: Atezolizumab, bevacizumab, and chemotherapy for newly diagnosed stage III or IV ovarian cancer: Placebocontrolled randomized phase III trial (IMagyn050/GOG 3015/ENGOT-OV39). J Clin Oncol 39(17): 1842-1855, 2021. PMID: 33891472. DOI: 10.1200/JCO.21.00306

51 Ray-Coquard IL, Savoye AM, Mouret-Reynier MA, Chabaud S, Derbel O, Kalbacher E, Leheurteur M, Martinez A, Cornila C, Martinez M, Bengrine L, Priou F, Cloarec N, Venat-Bouvet L, Selle F, Berton D, Collard O, Joly F and Tredan O: Efficacy and safety results from neopembrov study, a randomized phase II trial of neoadjuvant chemotherapy (CT) with or without pembrolizumab $(\mathrm{P})$ followed by interval debulking surgery and standard systemic therapy $\pm \mathrm{P}$ for advanced high-grade serous carcinoma (HGSC): A GINECO study. J Clin Oncol 39(suppl 15): 5500, 2021. DOI: 10.1200/JCO.2021.39.15_suppl.5500

52 Nemunaitis J, Kuhn J, Yu Y, Jay C, Oxendine I and Kumar P: TAG vaccine: Autologous tumor vaccine genetically modified to express GM-CSF and block production of TGFB2 (part 2). BioProcessing Journal 8(1): 38-44, 2015. DOI: 10.12665/J81.Maples.P2
53 Rocconi RP, Grosen EA, Ghamande SA, Chan JK, Barve MA, Oh J, Tewari D, Morris PC, Stevens EE, Bottsford-Miller JN, Tang M, Aaron P, Stanbery L, Horvath S, Wallraven G, Bognar E, Manning L, Nemunaitis J, Shanahan D, Slomovitz BM, Herzog TJ, Monk BJ and Coleman RL: Gemogenovatucel-T (Vigil) immunotherapy as maintenance in frontline stage III/IV ovarian cancer (VITAL): a randomised, double-blind, placebocontrolled, phase 2b trial. Lancet Oncol 21(12): 1661-1672, 2020. PMID: 33271095. DOI: 10.1016/S1470-2045(20)30533-7

54 Rocconi RP, Ghamande SA, Barve MA, Stevens EE, Aaron P, Stanbery L, Bognar E, Manning L, Nemunaitis JJ, O’Malley DM, Herzog TJ, Bradley J, Monk BJ and Coleman RL: Maintenance vigil immunotherapy in newly diagnosed advanced ovarian cancer: Efficacy assessment of homologous recombination proficient (HRP) patients in the phase IIb VITAL trial. J Clin Oncol 39(suppl 15): 5502, 2021. DOI: 10.1200/JCO.2021.39.15_suppl.5502

Received August 2, 2021

Revised September 6, 2021 Accepted September 7, 2021 